\title{
Calmodulin Is Involved in Membrane Depolarization-Mediated Survival of Motoneurons by Phosphatidylinositol-3 Kinase- and MAPK-Independent Pathways
}

\author{
Rosa M. Soler, Joaquim Egea, Gerard M. Mintenig, Cesar Sanz-Rodriguez, \\ Montse Iglesias, and Joan X. Comella \\ Grup de Neurobiologia Molecular, Departament de Ciències Mèdiques Bàsiques, Facultat de Medicina, \\ Universitat de Lleida, 25198 Lleida, Catalonia, Spain
}

\begin{abstract}
In the present work, we find that the elevation of extracellular $\mathrm{K}^{+}$concentration promotes the survival of chick spinal cord motoneurons in vitro deprived of any neurotrophic support. This treatment induces chronic depolarization of the neuronal plasma membrane, which activates L-type voltage-dependent $\mathrm{Ca}^{2+}$ channels, resulting in $\mathrm{Ca}^{2+}$ influx and elevation of the cytosolic free $\mathrm{Ca}^{2+}$ concentration. Pharmacological reduction of intracellular free $\mathrm{Ca}^{2+}$ or withdrawal of extracellular $\mathrm{Ca}^{2+}$ reversed the effects of depolarization on survival. The intracellular $\mathrm{Ca}^{2+}$ response to membrane depolarization developed as an initial peak followed by a sustained increase in intracellular $\mathrm{Ca}^{2+}$ concentration. The depolarizing treatment caused tyrosine phosphorylation of mitogen-activated protein kinase
\end{abstract}

(MAPK) without involving tyrosine kinase receptor activation. The calmodulin antagonist W13 inhibited the survivalpromoting effect induced by membrane depolarization but not the tyrosine phosphorylation of MAPK. Moreover, depolarization did not induce phosphatidylinositol-3 kinase (PI-3K) phosphorylation in our cells, and the PI-3K inhibitor wortmannin did not suppress the survival-promoting effect of $\mathrm{K}^{+}$treatment. These results suggest that calmodulin is involved in calciummediated survival of motoneurons through the activation of $\mathrm{PI}-3 \mathrm{~K}$ - and MAPK-independent pathways.

Key words: motoneuron; calmodulin; signal transduction; trophic factor; depolarization; apoptosis
During embryonic development of the vertebrate nervous system, approximately one half of all the neurons that are produced die as a result of a process known as natural or programmed cell death, which appears to be a strategy to adapt neuronal populations to their innervation target size and specificity (for review, see Oppenheim, 1991). It is now clear that specific target-derived neurotrophic factors play a decisive role in this (Barde, 1989; Oppenheim, 1989; Snider and Johnson, 1989). Motoneurons (MTNs) display the same behavior on trophic deprivation as other neuronal populations that respond to specific neurotrophic molecules (Comella et al., 1994). There is growing evidence that neuronal differentiation and survival may also be regulated by non-target-derived factors such as bioelectric activity (Franklin and Johnson, 1992; Franklin et al., 1995) or the cytoplasmic free $\mathrm{Ca}^{2+}$ concentration $\left(\left[\mathrm{Ca}^{2+}\right]_{\mathrm{i}}\right.$ ) (Collins and Lile, 1989; Collins et al., 1991; Johnson et al., 1992; Larmet et al., 1992; Murrell and Tolkosky, 1993; Franklin et al., 1995).

Previous studies have demonstrated that an increase in the $\left[\mathrm{Ca}^{2+}\right]_{\mathrm{i}}$ is able to activate Ras in PC12 cells (Rosen et al., 1994;

\footnotetext{
Received July 23, 1997; revised Nov. 21, 1997; accepted Nov. 26, 1997.

This work was supported by grants from FIS (94/1576), CICYT PN-SAF (970094), Ajuntament de Lleida, EU Programs Biomed (BMH4-CT96-0010) and Biotech (BIO4-CT96-0433), and Generalitat de Catalunya. We acknowledge the technical contribution of Eva Giné and Xavier Dolcet during the performance of this work. We are grateful to Josep E. Esquerda for helping with parts of this work and for his suggestions and criticisms regarding this manuscript. We thank Xavier Calomarde for helping with photographic work, and D. Martin-Zanca (Salamanca, Spain) for many discussions and the generous gift of antibodies.

Correspondence should be addressed to Joan X. Comella, Unit of Molecular Neurobiology, Departament de Ciències Mèdiques Bàsiques, Facultat de Medicina, Universitat de Lleida, Rovira Roure, 44, 25198 Lleida, Spain.

Copyright (C) 1998 Society for Neuroscience $0270-6474 / 98 / 181230-10 \$ 05.00 / 0$
}

for review, see Finkbeiner and Greenberg, 1996). Ras activation starts the sequential phosphorylation and activation of Raf, MEK, and MAPK protein kinases. This pathway provides a route through which $\mathrm{Ca}^{2+}$ influx could regulate cytoplasmic signaling and affect neuronal responses. The Ras pathway can also be activated by neurotrophins. In neurons, neurotrophins bind to specific tyrosine kinase receptors (Trks), resulting in tyrosine autophosphorylation of the receptor and tyrosine phosphorylation of Shc (for review, see Schlessinger, 1993; Segal and Greenberg, 1996).

PI-3K mediates another intracellular pathway that could be stimulated by increases on $\left[\mathrm{Ca}^{2+}\right]_{\mathrm{i}}$ or neurotrophin treatment and has been shown to be required for NGF-mediated survival in PC12 cells (Yao and Cooper, 1995). Moreover, this pathway has been shown to be involved in growth factor-mediated survival of primary neurons (Dudek et al., 1997; D’Mello et al., 1997) or other types of cells (Vemuri and McMorris, 1996). However, it seems that activation of the PI-3 kinase pathway is not essential in the promotion of neuronal survival because of high potassium (Dudek et al., 1997; D’Mello et al., 1997), although there is not complete agreement on this (Miller et al., 1997).

In the present work, we analyze the effect of elevated extracellular $\mathrm{K}^{+}$on the survival of primarily cultured MTNs from chick spinal cord, and we explore some of the molecular mechanisms involved therein. We have explored the possibility that calmodulin may serve as a second messenger to this effect. To that end we have monitored the MAPK signaling pathway in the presence of calmodulin antagonists. We show that calmodulin modulates survival but not the activation of the MAPK pathway when MTNs are submitted to depolarization. We also show that block- 
ade of the PI-3 kinase does not suppress the survival effects of $\mathrm{K}^{+}$ depolarization. Taken together, these results suggest that calmodulin is involved in the survival of depolarized MTNs and acts through mechanisms that are independent from both PI-3 kinase and MAPK.

\section{MATERIALS AND METHODS}

Cell isolation and culture. MTNs were purified from embryonic chicken according to Comella et al. (1994). Briefly, whole spinal cords were dissected out from 5.5-d-old Arbor Acres chick embryos (COPAGA, Lleida, Spain), rinsed in dissection buffer (137 mM NaCl, $2.7 \mathrm{~mm} \mathrm{KCl}$, $22.2 \mathrm{~mm}$ glucose, $25 \mathrm{~mm}$ HEPES buffer, $\mathrm{pH}$ 7.4, $20 \mathrm{IU} / \mathrm{ml}$ penicillin, and $20 \mathrm{mg} / \mathrm{ml}$ streptomycin) (GHEBS), and incubated in $0.05 \%$ trypsin solution for $15 \mathrm{~min}$ at $37^{\circ} \mathrm{C}$. Cells were then dissociated by pipetting through a Gilson blue cone in complete culture medium (Leibovitz's 15 medium supplemented with a final concentration of $18 \mathrm{~mm}$ glucose, 22.5 $\mathrm{mm}$ bicarbonate, $2.5 \mathrm{~mm}$ glutamine, and $20 \mathrm{U} / \mathrm{ml}$ penicillin plus $20 \mu \mathrm{g} / \mathrm{ml}$ streptomycin) (L15) containing 10\% heat-inactivated horse serum (Life Technologies, Gaithersburg, MD) (L15H). The single-cell solution was layered onto $5 \mathrm{ml}$ of L15 medium and 3.5\% (wt/vol) BSA and spun at $100 \times g$ for $5 \mathrm{~min}$ to remove cell debris. Cells were resuspended in GHEBS and layered onto $4 \mathrm{ml}$ of $28.75 \%$ (vol/vol) Nycodenz [5-( $N-2$, 3-dihydroxypropylacetamido)-2, 4, 6-tri-iodo- $N$, $N^{\prime}$-bis (2, 3 dihydroxypropyl) isophthalamide] (Nycomed AS, Norway) (supplied as an isotonic sterile solution of $1.15 \mathrm{~g} / \mathrm{ml}$ density) in GHEBS and centrif uged at $400 \times g$ for $10 \mathrm{~min}$. The intermediate layer was collected and transferred to an appropriate amount of $\mathrm{L} 15 \mathrm{H}$, and cells were counted with a hemocytometer. For survival experiments, MTNs were plated in 96-well culture dishes (Corning, Corning, NY) precoated with poly-DL-ornithine $($ PORN) $(30 \mu \mathrm{g} / \mathrm{ml}$ for $30 \mathrm{~min})$ and laminin $(2 \mu \mathrm{g} / \mathrm{ml}$ for $1 \mathrm{hr})$ (Life Technologies), and seeded at a density of 15,000 cells per well. For Western blot and immunoprecipitation experiments, $2-3 \times 10^{6}$ cells were plated in precoated $60 \mathrm{~mm}$ culture dishes (Corning).

PC12 cells were grown on $75 \mathrm{~cm}^{2}$ culture dishes (Corning) in DMEM (Sigma, St. Louis, MO) supplemented with $6 \%$ heat-inactivated fetal calf serum (Life Technologies) and 6\% heat-inactivated horse serum (Life Technologies) containing $10 \mathrm{mM}$ HEPES and $20 \mathrm{Ul} / \mathrm{ml}$ penicillin plus 20 $\mu \mathrm{g} / \mathrm{ml}$ streptomycin. For Western blot and immunoprecipitation experiments, 5-6 $610^{6} \mathrm{PC1}$ cells were plated in $60 \mathrm{~mm}$ culture dishes (Corning) precoated with PORN.

All cultures were kept at $37^{\circ} \mathrm{C}$ in a saturating humidity atmosphere of 95\% air, $5 \% \mathrm{CO}_{2}$

Evaluation of neuronal survival and apoptosis. Unless indicated otherwise, MTNs were cultured in the presence of a saturating concentration $(300 \mu \mathrm{g} / \mathrm{ml})$ of muscle extract (MEX) for $48 \mathrm{hr}$ (Comella et al., 1994). At this time, cells were washed with $\mathrm{L} 15 \mathrm{H}$ and $50 \mu \mathrm{l}$ of assay medium containing the appropriate amount of supplements or drugs. The number of cells was determined in the central area of every well using a $20 \times$ power objective on a phase-contrast inverted microscope. Only cells bearing neurites longer than two cell diameters were included in counts. This value represented our corrected $100 \%$ initial survival. Counts were performed every $24 \mathrm{hr}$ in precisely the same microscopic field throughout the duration of the experiment, and survival was expressed as a percentage of neuronal counts with respect to the $100 \%$ initial value. Values shown are the mean \pm SEM of these percentages for eight wells; each experiment was repeated at least three times. Where applicable, statistical analysis was performed with the nonparametric test for two independent samples: Mann-Whitney, Kruskal-Wallis test and one-way ANOVA and least-significant difference test.

To assess whether a given treatment induced an apoptotic cell death process, cultures were stained with the Hoechst 33258 dye. MTNs having grown in $35 \mathrm{~mm}$ culture wells for $48 \mathrm{hr}$ in the presence of saturating concentrations of MEX were washed with $\mathrm{L} 15 \mathrm{H}$ and were grown for an additional 15 min with NE, MEX, 30K, or W13 medium. At this time, media were removed, and cells were washed twice with PBS and fixed with 4\% (wt/vol) paraformaldehyde (Fluka, Neu-Ulm, Germany) in PBS for $15 \mathrm{~min}$. Thereafter, neurons were washed three times with PBS and stained for $30 \mathrm{~min}$ with $0.05 \mu \mathrm{g} / \mathrm{ml}$ Hoechst 33258 (Sigma). Cultures were then washed twice with PBS and mounted with glass coverslips using Fluoprep (Biomerieux) as mounting medium. Stained cells were observed and counted with a vertical microscope equipped with epifluorescence and UV filters.

Measurement of intracellular $\mathrm{Ca}^{2+}$. Neurons were loaded with fura-2 $\mathrm{AM}$, and intracellular $\mathrm{Ca}^{2+}$ levels were measured microscopically in individual cell bodies. Cells were grown on PORN-laminin-coated glass coverslips and loaded with $2 \mu \mathrm{M}$ fura-2 AM (Molecular Probes, Eugene, OR) for 1-2 hr. Cells were then washed in GHEBS-fura-1 AM solution (GHEBS supplemented with $2 \mathrm{~mm} \mathrm{CaCl}_{2}$ and $1.5 \mathrm{mM} \mathrm{Cl}_{2} \mathrm{Mg}$ ) and incubated for $30 \mathrm{~min}$ at $37^{\circ} \mathrm{C}$ to allow hydrolysis of ester. $\mathrm{Ca}^{2+}$ measurements were recorded on a Zeiss Axiovert 10 inverted microscope equipped with a Zeiss MPM microscope photometer. Light from a $75 \mathrm{~W}$ xenon lamp combined with interference filters of $340 \pm 10 \mathrm{~nm}$ and $380 \pm$ $10 \mathrm{~nm}$ in a wheel changer was deflected by a dichroic mirror at $425 \mathrm{~nm}$ into a $40 \times$ Plan-Neofluar objective, and fluorescence emission was collected through a 500-530 nm interference filter into a photomultiplier (Hamamatsu, R928). Excitation at $380 \mathrm{~nm}$ was attenuated by a corrective filter to compensate for higher attenuation of $340 \mathrm{~nm}$ light along the optic path. The output of the photomultiplier was fed to a specially written computer program (FFP, Zeiss). Random fields of neuronal cell bodies (five cells/field) were examined in individual dishes to determine pretreatment calcium values. Media containing high $\mathrm{K}^{+}$or drugs were quickly substituted for GHEBS, and calcium measurements were made at different times after medium replacement. Signal calibration as a function of intracellular $\mathrm{Ca}^{2+}$ was performed using standard $\mathrm{Ca}^{2+}$ solutions (Molecular Probes) and was converted to $\mathrm{Ca}^{2+}$ concentrations as described by Grynkiewicz et al. (1985). Data from different culture dishes receiving the same treatment were pooled. Values for $\mathrm{Ca}^{2+}$ are expressed as the mean concentrations \pm SEM.

Tyrosine phosphorylation assay and immunodetection of $p 85$ subunit of $P I-3 K$. For immunodetection experiments, we determined that a minimum of $2-3 \times 10^{6}$ MTNs were needed for each treatment (i.e., lane on SDS-PAGE gel). Alternatively an $80 \%$ confluence $60 \mathrm{~mm}$ culture dish of PC12 cells was used for each treatment. MTNs were plated on $60 \mathrm{~mm}$ tissue culture dishes and grown in the presence of MEX for 2 or $3 \mathrm{~d}$ before exposure to the agents was initiated. At appropriate times, MTNs or PC12 cells were rinsed three times with L15H or DMEM without serum, respectively, and were maintained for $3 \mathrm{hr}$ in the presence of fresh medium containing the appropriate drug. After this time, PC12 cells or MTNs were incubated in medium containing NGF $(200 \mathrm{ng} / \mathrm{ml})$ or $30 \mathrm{~mm}$ $\mathrm{K}^{+}$, respectively, for $5 \mathrm{~min}$ at $37^{\circ} \mathrm{C}$. At the end of the treatments, cultures were rinsed rapidly in ice-cold PBS and solubilized at $4^{\circ} \mathrm{C}$ in $0.4 \mathrm{ml}$ of Tris/NP-40 lysis buffer (20 mm Tris, pH 7.4, $150 \mathrm{~mm} \mathrm{NaCl,} 2$ mm EDTA, $1 \mathrm{~mm}$ EGTA, $1 \%$ NP-40, $0.5 \mathrm{~mm}$ sodium orthovanadate, $1 \mathrm{~mm}$ phenylmethylsulfonylfluoride, $10 \mu \mathrm{g} / \mathrm{ml}$ aprotinin, $2 \mathrm{~mm}$ benzamide, and 20 $\mu \mathrm{g} / \mathrm{ml}$ leupeptin). After a $15 \mathrm{~min}$ incubation on ice, the samples were rotated orbitally for $30 \mathrm{~min}$ at $4^{\circ} \mathrm{C}$ and spun in a microcentrifuge for 15 $\min$ at $4^{\circ} \mathrm{C}$ to remove nuclei and cellular debris. The amount of protein in lysates was quantified by the BIO-RAD Dc Protein Assay (Bio-Rad, Munich, Germany).

To determine the level of tyrosine phosphorylation of MAPK, cell lysates were immunoprecipitated with specific antibodies. Supernatants were subjected to MAPK immunoprecipitation (MAPK-IP) overnight at $4^{\circ} \mathrm{C}$ with an anti-extracellular-regulated kinase 2 (ERK2) polyclonal antibody (Transduction Laboratories, Lexington, KY), as described by the provider. The immunocomplexes were precipitated for $1-2 \mathrm{hr}$ at $4^{\circ} \mathrm{C}$ with protein A-Sepharose beads, electrophoresed in SDS-PAGE gels, and transferred onto polyvinylidene difluoride (PVDF) Immobilon-P transfer membrane filters (Millipore, Bedford, MA). Membranes were blocked with TBS-T20 (20 mM Tris-HCl, pH 7.4, $150 \mathrm{~mm} \mathrm{NaCl}, 0.05 \%$ Tween-20) containing 5\% BSA for $1 \mathrm{hr}$ at room temperature and blotted with the 4G10 anti-phosphotyrosine monoclonal (anti-PTyr) antibody for $1 \mathrm{hr}$ at room temperature. Membranes were incubated with antimouse IgG antibody peroxidase conjugated for $1 \mathrm{hr}$ at room temperature and developed with the enhanced chemiluminescence Western blotting detection system from Amersham (Arlington Heights, IL). Alternatively, tyrosine phosphorylation of MAPK was detected in cytoplasmatic lysates. Thus $20 \mu \mathrm{g}$ of cytoplasmatic protein per well was separated by SDS-PAGE, transferred onto PVDF membranes, and blotted with the anti-PTyr antibody as described above. Filters from tyrosine phosphorylation assays were stripped with $100 \mathrm{~mm} \beta$-mercaptoethanol, 2\% SDS in $62.5 \mathrm{~mm}$ Tris- $\mathrm{HCl}, \mathrm{pH} 6.7$, for $30 \mathrm{~min}$ at $50^{\circ} \mathrm{C}$, and processed for the immunodetection of ERK proteins with a mouse monoclonal anti-panERK antibody (Transduction Laboratories).

Immunodetection of $\mathrm{p} 85$ subunit of PI-3K was performed in anti-PTyr immunoprecipitates and total cell lysates. To immunoprecipitate $\mathrm{p} 85$, protein extracts from MTNs depolarized with $30 \mathrm{~K}^{+}$for 1 min or from PC12 cells stimulated with NGF for 1 min were subjected to immunoprecipitation overnight at $4^{\circ} \mathrm{C}$ with the anti-PTyr antibody. Immunocomplexes were precipitated with protein A-Sepharose coupled to rabbit 

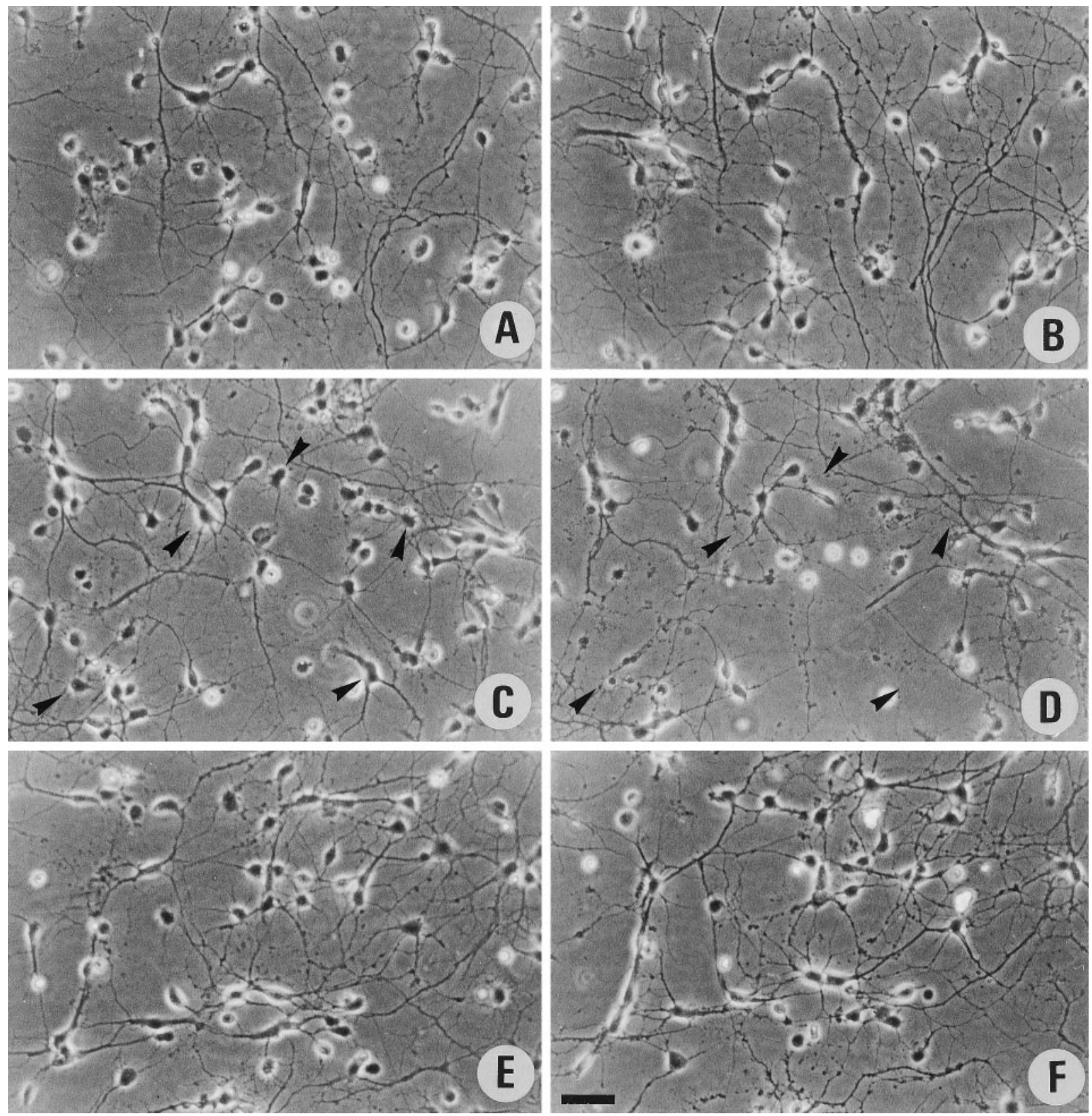

Figure 1. Phase-contrast micrographs showing the effects of MEX withdrawal and the ability of high $\mathrm{K}^{+}$to promote the survival of MTNs deprived of MEX. MTNs were cultured for $2 \mathrm{~d}$ in the presence of MEX medium, and thereafter the culture medium was replaced with MEX $(A, B)$, NE $(C, D)$, or $30 \mathrm{~K}(E, F)$. The same microscopic fields were photographed at time $0(A, C, E)$ and after $24 \mathrm{hr}(B, D, F)$. The arrowheads indicate neurons that died after MEX deprivation. Scale bar, $50 \mu \mathrm{m}$.

anti-mouse polyclonal antibody (Sigma). Precipitates or alternatively 20 $\mu \mathrm{g}$ of protein extracts per well were electrophoresed and transferred as described above. Filters were blotted with an anti-p85 polyclonal antibody (UBI) as described by the provider.

Reagents. 1,2-bis 2-aminophenoxyethane- $N, N, N, N^{\prime}$-tetra-acetic acid (acetomethyl) ester (BAPTA/AM) was obtained from Molecular Probes. Bay K 8644 was from Calbiochem (La Jolla, CA). Nifedipine, amiloride, verapamil, wortmannin, $\mathrm{N}$-(4-aminobutyl)-5-chloro-2-naphthalenesulfonamide hydrochloride (W13), $N$-(4-aminobutyl)-2-naphthalenesulfonamide hydrochloride (W12), anti-mouse IgG antibody peroxidase-conjugated, and the other biochemicals were obtained from Sigma. NGF was prepared at the laboratory from mouse salivary glands, as described by Mobley et al. (1976). 4G10 anti-PTyr antibody was a generous gift of D. Martín-Zanca (Salamanca, Spain)

\section{RESULTS}

\section{Elevated extracellular $\mathrm{K}^{+}$promotes the survival of spinal cord motoneurons}

MTNs were initially cultured in a saturating concentration of MEX for $2 \mathrm{~d}$. Afterward, the culture medium was replaced and the different conditions were established. On readdition of a medium containing MEX, $>90 \%$ of the MTNs remained alive after an additional $24 \mathrm{hr}$ of culture (Fig. 1). However, when they were deprived of MEX and maintained in the basal medium, i.e., $\mathrm{L} 15 \mathrm{H}$, a significantly lower $(p<0.005)$ percentage of MTNs $(\sim 50 \%)$ survived (Fig. $2 A)$. 
A

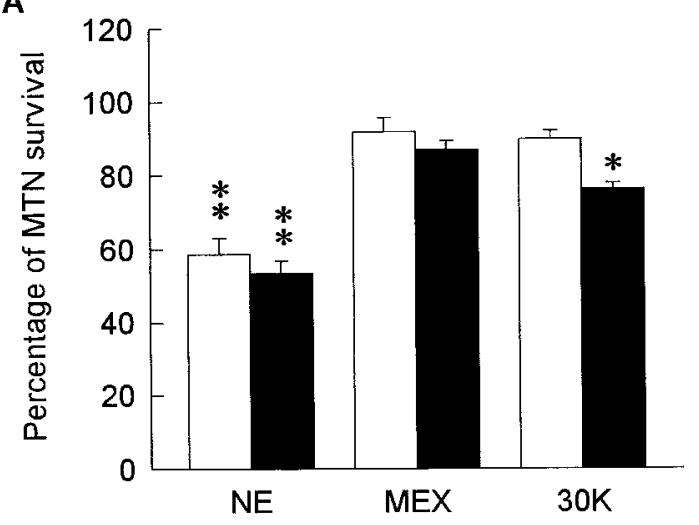

B

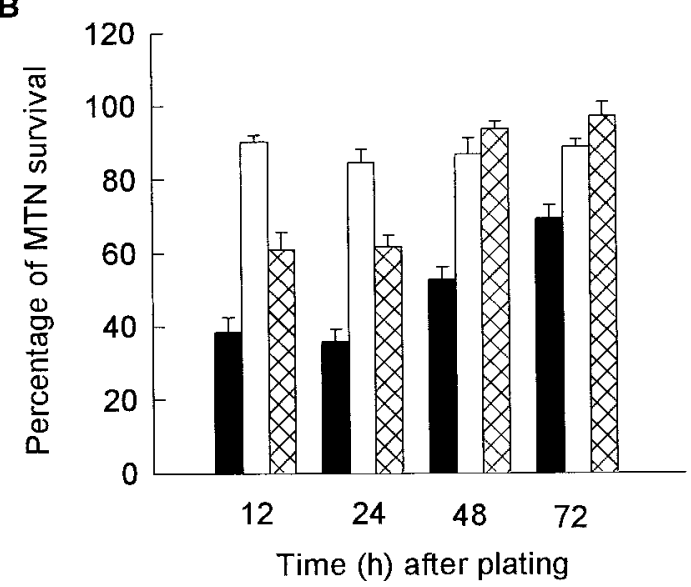

Figure 2. Effect of elevated extracellular $\mathrm{K}^{+}$levels on the survival of MTNs. $A$, Percentages of MTN survival after $24 \mathrm{hr}$ (open bars) or $48 \mathrm{hr}$ (black bars) in control cultures (NE and $M E X)$ or cultures treated with high potassium $(30 \mathrm{~K})$. B , Percentages of MTN survival $24 \mathrm{hr}$ after treatment with NE (black bars), MEX (open bars), and 30K (cross-hatched bars) applied 12, 24, 48, and $72 \mathrm{hr}$ after plating. Values are the mean \pm SEM. ${ }^{*} p<0.05$ and ${ }^{* *} p<0.005$ in $A$ indicate values significantly different from sibling MEX-treated cultures.

To investigate how $\left[\mathrm{Ca}^{2+}\right]_{\mathrm{i}}$ can influence the survival of MTNs, we studied the effects of adding $\mathrm{KCl}$ to cultures of MTNs deprived of any specific trophic factor. This treatment induces chronic depolarization of the neuronal plasma membrane, which in turn activates voltage-dependent $\mathrm{Ca}^{2+}$ channels, resulting in $\mathrm{Ca}^{2+}$ influx and elevation of $\left[\mathrm{Ca}^{2+}\right]_{\mathrm{i}}$ (Lipscombe et al., 1988). The effect of extracellular $\mathrm{K}^{+}$on MTN survival was dose dependent. After $24 \mathrm{hr}$, an almost complete preservation of survival $(90 \%)$ was obtained with a medium containing $30 \mathrm{~mm} \mathrm{~K}^{+}(30 \mathrm{~K})$ (Fig. 2A). At $48 \mathrm{hr}$ the rate of MTN survival in $30 \mathrm{~K}$-treated cultures remained higher than that of cultures grown in $\mathrm{L} 15 \mathrm{H}$ culture medium without MEX (NE); however, the high $\mathrm{K}^{+}$ medium did not support as much MTN survival as MEX at the time $(p<0.05)$ (Fig. $2 A)$.

To determine whether the ability of high $\mathrm{K}^{+}$to support the survival of MEX-deprived MTNs was related to the time of cells in vitro, we tested the ability of $30 \mathrm{~K}$ to keep MTNs alive at different times after plating. MTNs were initially cultured in the presence of MEX for different time periods and then transferred to $30 \mathrm{~K}$ medium. Survival was assessed $24 \mathrm{hr}$ after medium replacement. When MTNs were cultured for either 12 or $24 \mathrm{hr}$ in a medium containing MEX and then changed to a medium con- taining $30 \mathrm{~K}$, the survival percentage was $\sim 60 \%$ in both cases. When MTNs were allowed to grow in the presence of MEX for 48 or $72 \mathrm{hr}, 30 \mathrm{~K}$ supported the survival of $>90 \%$ of the cells. Thus, although MEX maintains MTN survival from the beginning of the culture period $(12 \mathrm{hr})$, the ability of high $\mathrm{K}^{+}$to do so is not fully developed until $48 \mathrm{hr}$ in culture with MEX (Fig. 2B).

\section{Role of cytosolic free $\mathrm{Ca}^{2+}$ in the survival of MTNs in high $\mathrm{K}^{+}$medium}

The " $\mathrm{Ca}^{2+}$ set-point hypothesis" proposes that the maintenance of an appropriate $\left[\mathrm{Ca}^{2+}\right]_{\mathrm{i}}$ can sustain the survival of neurons in the absence of neurotrophic factors (Koike et al., 1989). If such a mechanism did operate in MTNs, experimental prevention of the increase in $\left[\mathrm{Ca}^{2+}\right]_{\mathrm{i}}$ induced by depolarization should abolish the rescuing effects of treating the cultures with a high $\mathrm{K}^{+}$medium. To test this hypothesis, we performed experiments using the intracellular $\mathrm{Ca}^{2+}$ chelator BAPTA/AM. This drug is a membrane-permeable acetoxymethyl ester, which is hydrolyzed by intracellular esterases, so that BAPTA is retained in the cytoplasm. BAPTA/AM did not modify the ability of MEX to maintain MTN survival. In MEX-treated cultures the survival was $83 \pm 3 \%$, whereas in MEX-treated cultures to which $20 \mu \mathrm{M}$ BAPTA/AM was added the observed survival was $82 \pm 3 \%$. However, BAPTA/AM completely prevented the effects of $30 \mathrm{~K}$ on MTN survival. In cultures treated with $30 \mathrm{~K}$ plus $20 \mu \mathrm{M}$ BAPTA/AM (Fig. $3 A$ ), the survival percentage decreased significantly $(44 \pm 3 \% ; p<0.05)$ with respect to those treated with $30 \mathrm{~K}$ alone $(85 \pm 4 \%)$. Thus, these results suggest that an increase in $\left[\mathrm{Ca}^{2+}\right]_{\mathrm{i}}$ is required for high $\mathrm{K}^{+}$medium to rescue MEXdeprived MTNs.

To ascertain whether the incremental increase in $\left[\mathrm{Ca}^{2+}\right]_{\mathrm{i}}$ in high $\mathrm{K}^{+}$-treated cells results from the influx of $\mathrm{Ca}^{2+}$ from the extracellular medium, we tested the effect of the withdrawal of extracellular $\mathrm{Ca}^{2+}$ using the extracellular calcium chelator EGTA. When $1.5 \mathrm{~mm}$ EGTA was added to $30 \mathrm{~K}$-treated cultures, the survival of MTNs decreased to $61 \pm 3 \%$ (Fig. $3 A$ ). On the other hand, when the same concentration of EGTA was added to MEX-treated cultures, the survival percentage $(80 \pm 3 \%)$ was not significantly different from that observed in cells treated with MEX only (Fig. 3A). This finding indicates that the increase in $\left[\mathrm{Ca}^{2+}\right]_{\mathrm{i}}$ is attributable to an influx of $\mathrm{Ca}^{2+}$ from the extracellular medium.

\section{Voltage-gated $\mathrm{Ca}^{2+}$ channel antagonists block the survival-promoting effect of high $\mathrm{K}^{+}$medium}

To analyze which types of voltage-gated $\mathrm{Ca}^{2+}$ channels are involved in the rescuing effects of depolarization, we tested different $\mathrm{Ca}^{2+}$ channel antagonists. Amiloride, a T-type voltagegated $\mathrm{Ca}^{2+}$ channel antagonist, did not affect the survivalpromoting effect of $30 \mathrm{~K}$, suggesting that channels of this type were not involved (Fig. 4A). L-type $\mathrm{Ca}^{2+}$ channel antagonists, such as nifedipine and verapamil, prevented the ability of high $\mathrm{K}^{+}$ to maintain survival of MTNs. The effects of these drugs were dose dependent. The percentage of MTN survival in high $\mathrm{K}^{+}$ plus $1 \mu \mathrm{M}$ nifedipine was $62 \pm 3 \%$; thus the values of survival in high $\mathrm{K}^{+}(98 \pm 3 \%)$ were similar to those found in NE control cultures $(61 \pm 2 \%)$ (Fig. $4 A$ ). Toxicity of the drug was tested by adding $1 \mu \mathrm{M}$ nifedipine to MEX-treated cultures. The percentages of survival in drug-treated and untreated cultures were not significantly different (data not shown). Likewise, the effects of verapamil, which blocks the L-type $\mathrm{Ca}^{2+}$ channels independently of depolarization (Striessing et al., 1986), were similar to those 
A

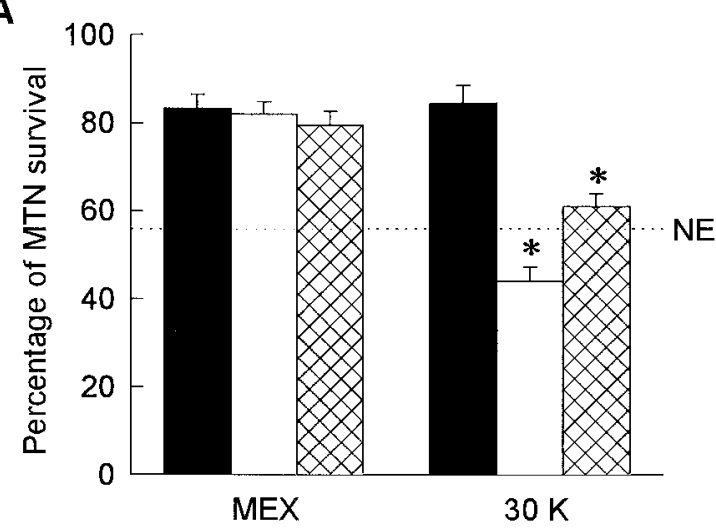

B

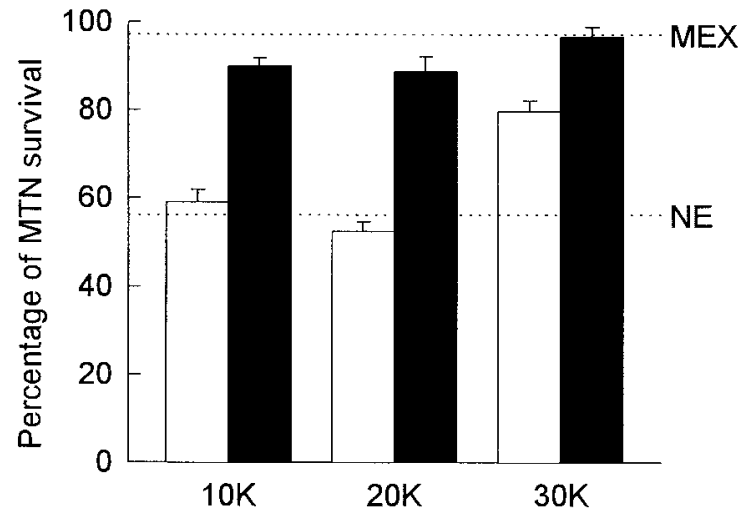

Figure 3. Effect of BAPTA/AM, EGTA, and Bay K 8644 on the survival of depolarized MTNs. $A$, Percentages of MTN survival after treatment during $24 \mathrm{hr}$ with no drugs (black bars), $20 \mu \mathrm{M}$ BAPTA/AM (open bars), or $1.5 \mathrm{~mm}$ EGTA (cross-hatched bars) in MEX or $30 \mathrm{~K}$ medium. B, Percentage of MTN survival after $24 \mathrm{hr}$ in vitro in cultures supplemented with 10, 20, and $30 \mathrm{~mm} \mathrm{KCl,} \mathrm{with} \mathrm{(black} \mathrm{bars)} \mathrm{or} \mathrm{without} \mathrm{(open} \mathrm{bars)} 1 \mu \mathrm{M}$ Bay K. Broken lines show survival of cells in sibling control cultures maintained in $\mathrm{NE}(A)$ or in MEX and $\mathrm{NE}(B)$ culture medium for the same culture period. Values are the mean \pm SEM. Asterisks in $A$ indicate values significantly different $(p<0.05)$ from control, 30K-treated cultures.

obtained with nifedipine, except for the fact that verapamil was less effective (Fig. $4 A$ ).

To further investigate the role of L-type $\mathrm{Ca}^{2+}$ channels in mediating the depolarization survival effects, we used Bay $\mathrm{K}$ 8644. This L-type $\mathrm{Ca}^{2+}$ channel agonist is known to shift the voltage dependence of the $\mathrm{Ca}^{2+}$ channel opening to more negative potentials and to prolong the channel opening (Nowycky et al., 1985). As would be expected, Bay K did not have a direct effect on MTN survival in our cultures (data not shown), but it clearly potentiated the effect of high $\mathrm{K}^{+}$. At suboptimal concentrations of $\mathrm{K}^{+}(10$ or $20 \mathrm{~mm})$, MTN survival in Bay K-treated cultures was similar to that found in $30 \mathrm{~K}$-treated cultures (Fig. $3 B$ ). Taken together, these results imply that L-type $\mathrm{Ca}^{2+}$ channels are the mediators of the $\mathrm{Ca}^{2+}$ influx that promotes the survival-enhancing effect of high $\mathrm{K}^{+}$medium in MTNs.

\section{Effects of high $\mathrm{K}^{+}$medium on intracellular $\mathrm{Ca}^{2+}$ concentration}

Elevation of the extracellular $\mathrm{K}^{+}$concentration to a level that promotes neuronal survival in different neuronal populations is associated with a sustained elevation of intracellular calcium
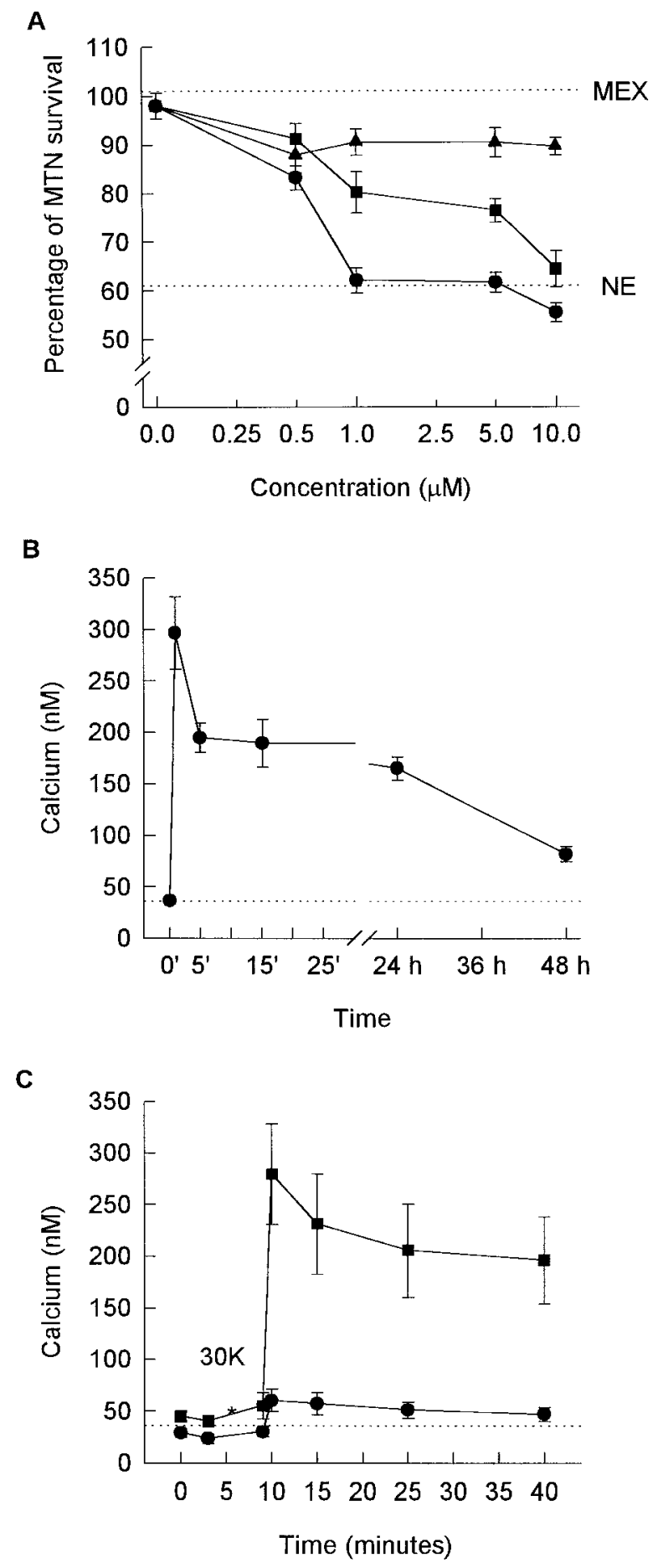

Figure 4. Effect of $\mathrm{Ca}^{2+}$ channel antagonists on MTN survival and on $\left[\mathrm{Ca}^{2+}\right]_{\mathrm{i}} \cdot A$, Percentages of MTN survival in cultures supplemented with $30 \mathrm{~K}$ are plotted against different doses of the $\mathrm{Ca}^{2+}$ channel antagonists nifedipine ( filled circles), verapamil ( filled squares), and amiloride ( filled triangles). Survival was evaluated $24 \mathrm{hr}$ after treatment. Broken lines show survival of cells in sibling control cultures maintained in MEX or in NE culture medium for the same period of time. Survival values are plotted as the mean \pm SEM. $B$, Effect of extracellular high $\mathrm{K}^{+}$on $\left[\mathrm{Ca}^{2+}\right]_{\mathrm{i}} . \mathrm{KCl}$ $(30 \mathrm{mM})$ was added to the culture medium of MTNs at $0 \mathrm{~min}$, and $\left[\mathrm{Ca}^{2+}\right]_{\mathrm{i}}$ was measured 1, 5, and $15 \mathrm{~min}$, and $24 \mathrm{and} 48 \mathrm{hr}$ after exposition. $C$, Effect of the addition of high potassium $(* 30 \mathrm{~K})$ after $10 \mathrm{~min}$ in the presence of $10 \mu \mathrm{M}$ nifedipine ( filled circles) and $10 \mu \mathrm{M}$ amiloride (filled squares). In $B$ and $C\left[\mathrm{Ca}^{2+}\right]_{\mathrm{i}}$ is plotted as the mean \pm SEM, and the broken lines represent the average baseline calcium level in control medium. 
(Collins et al., 1991; Koike and Tanaka, 1991). To study the intracellular $\mathrm{Ca}^{2+}$ response to membrane depolarization in MTNs, cells were loaded with fura-2 AM, and $\mathrm{Ca}^{2+}$ levels were measured microscopically in individual cell bodies. The basal $\left[\mathrm{Ca}^{2+}\right]_{\mathrm{i}}$ in MTNs cultured for $2 \mathrm{~d}$ in the presence of MEX was $36.3 \pm 2.60 \mathrm{~nm}$ (mean of 25 cells from five different experiments) (Fig. 4B). When the neurons were exposed to $30 \mathrm{~K},\left[\mathrm{Ca}^{2+}\right]_{\mathrm{i}}$ increased rapidly within the first minute to $297 \pm 35 \mathrm{~nm}$ (mean of 25 cells from five different experiments). After $15 \mathrm{~min}$ the concentration decreased to $189 \pm 23 \mathrm{~nm}$ (10 cells from two different experiments); after $24 \mathrm{hr}$ in the continued presence of $30 \mathrm{~K}$ this value was $165 \pm 11 \mathrm{~nm}$ ( 33 cells from six different experiments), and after $48 \mathrm{hr}$ of exposure of the MTNs to a $30 \mathrm{~K}$ medium, $\left[\mathrm{Ca}^{2+}\right]_{\mathrm{i}}$ decreased to $82 \pm 7.5 \mathrm{~nm}$ (20 cells from four different experiments). This value was still significantly higher than that found in the basal culture conditions. The addition of $1.5 \mathrm{~mm}$ EGTA or $20 \mu \mathrm{M}$ BAPTA/AM to the $30 \mathrm{~K}$ medium completely suppressed the intracellular calcium elevation observed at 1 and 15 min (data not shown). Therefore, we observed a good correspondence between neuronal survival and the variation of $\left[\mathrm{Ca}^{2+}\right]_{\mathrm{i}}$ caused by chronic depolarization.

The dihydropyridine L-type calcium channel antagonist nifedipine suppressed the elevation of intracellular calcium. When the extracellular $\mathrm{K}^{+}$concentration was raised to $30 \mathrm{~mm}$ in cultures previously exposed to $10 \mu \mathrm{M}$ nifedipine for $10 \mathrm{~min}$, the $\left[\mathrm{Ca}^{2+}\right]_{\mathrm{i}}$ increased from $30 \pm 5 \mathrm{nM}$ to $60.5 \pm 11 \mathrm{~nm}$ within $1 \mathrm{~min}$, but decreased to $47 \pm 7 \mathrm{~nm}$ within $30 \mathrm{~min}$ (Fig. $4 C$ ). The T-type $\mathrm{Ca}^{2+}$ channel antagonist amiloride did not affect the increase in the $\left[\mathrm{Ca}^{2+}\right]_{\mathrm{i}}$ after addition of $30 \mathrm{mM} \mathrm{K}^{+}$to the culture medium (Fig. $4 C)$. These results suggest that the observed increase in $\left[\mathrm{Ca}^{2+}\right]_{\mathrm{i}}$ after depolarization of the plasma membrane by high $\mathrm{K}^{+}$is attributable to $\mathrm{Ca}^{2+}$ entry from the extracellular space through L-type $\mathrm{Ca}^{2+}$ channels.

\section{Role of calmodulin in depolarization-enhanced survival of MTNs}

A possible role for calmodulin in mediating the effect of depolarization on neuronal survival has been suggested previously (Gallo et al., 1987; Hack et al., 1993; Franklin et al., 1995). To determine whether calmodulin antagonists play a role in neuronal survival in depolarized MTNs, we tested W13, a specific calmodulin antagonist that binds to calmodulin and inhibits $\mathrm{Ca}^{2+}$ calmodulin-regulated enzyme activities. As a control we used W12, a related compound that lacks chlorine in its molecule and is a much less effective calmodulin blocker than W13 (Hidaka et al., 1981; Hidaka and Tanaka, 1983). Application of $5 \mu \mathrm{g} / \mathrm{ml}$ of W13 to $30 \mathrm{~K}$-treated cultures (Fig. $5 A$ ) reversed the survival to the level found in NE-treated cultures. The same dose applied to MEX-supplemented neurons had no effect on survival. On the other hand, W12 (5 $\mu \mathrm{g} / \mathrm{ml})$ had no effect on neuronal survival in any of the culture conditions tested (Fig. $5 A$ ). To assess whether W13 suppresses the survival effects of depolarization, therefore inducing neuronal death, we have quantified the percentage of apoptotic MTNs after W13 treatment. Experiments were performed with the Hoechst 33258 dye, which binds specifically to the double-stranded DNA and emits at 490-500 nm when excited at $360 \mathrm{~nm}$. Apoptotic cells display a highly condensed DNA that is normally fragmented in two or more chromatin aggregates. In MTN cultures grown in the presence of MEX or $30 \mathrm{~K}$ the percentage of cells displaying this morphology was found to be $2.2 \%$ and $2.1 \%$, respectively; however, after $15 \mathrm{hr}$ of MEX deprivation, a substantial increase $(4,8 \%)$ in the percentage of cells that

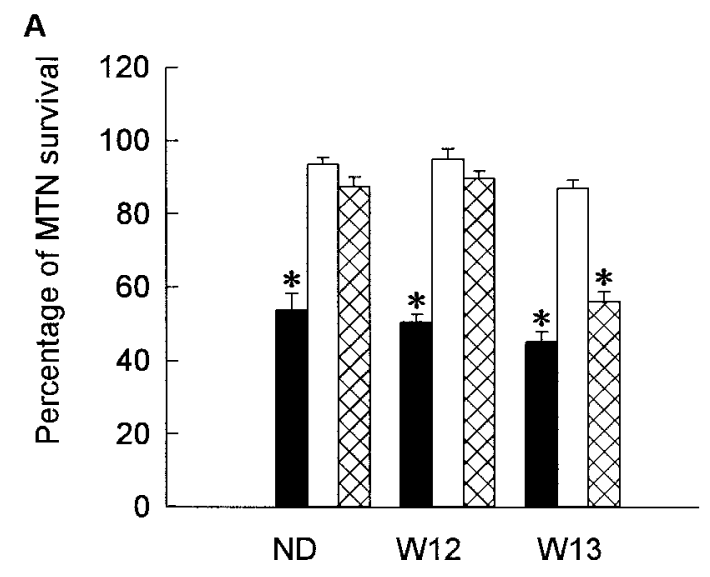

$\mathbf{B}$

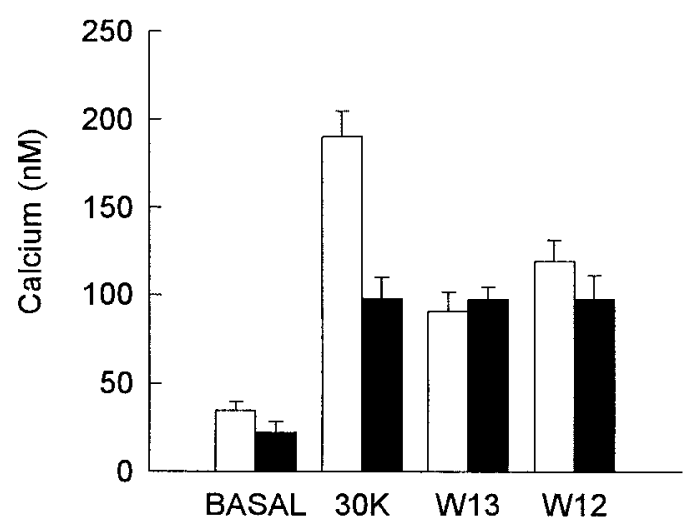

Figure 5. Effect of calmodulin antagonists on survival and on $\left[\mathrm{Ca}^{2+}\right]_{\mathrm{i}} \cdot A$, Percentages of MTN survival after $24 \mathrm{hr}$ in NE cultures (open bars), MEX-treated cultures (black bars), and high potassium-treated cultures (cross-hatched bars). Groups of bars represent survival in cultures without drugs $(N D)$ or cultures treated with $5 \mu \mathrm{g} / \mathrm{ml} \mathrm{W12}$ or W13. Values are the mean \pm SEM. Asterisks indicate values significantly different $(p<0.05)$ from control, MEX-treated cultures. $B$, Intracellular calcium level in untreated cultures $(B A S A L)$ and in cultures treated with high potassium alone $(30 K)$ or high potassium supplemented with $5 \mu \mathrm{g} / \mathrm{ml}$ W12 (W12) or $5 \mu \mathrm{g} / \mathrm{ml} \mathrm{W13}\left(\right.$ W13). $\left[\mathrm{Ca}^{2+}\right]_{\mathrm{i}}$ was measured after $5 \mathrm{~min}$ (open bars) and 24 $\mathrm{hr}$ (black bars) of treatment. $\left[\mathrm{Ca}^{2+}\right]_{\mathrm{i}}$ is plotted as the mean $\pm \mathrm{SEM}$.

displayed apoptotic nuclei was found. In $5 \mu \mathrm{g} / \mathrm{ml} \mathrm{W13-30K-}$ treated cultures, this percentage was found to be similar $(4.3 \%)$ to that found in MEX-deprived cultures.

These results suggest that calmodulin plays a role in mediating the survival effects of depolarization. It has been suggested, however, that some calmodulin antagonists (e.g., calmidazolium and W7) can interact with voltage-dependent calcium channels and reduce $\mathrm{Ca}^{2+}$ influx (Greenberg et al., 1987; Doroshenko et al., 1988; Franklin et al., 1995). To ascertain whether W12 and W13 might affect the sustained elevation of intracellular $\mathrm{Ca}^{2+}$ caused by depolarization in MTNs, cells were depolarized with $30 \mathrm{~K}$ in the presence of the calmodulin antagonists, and $\left[\mathrm{Ca}^{2+}\right]_{i}$ was measured. After $5 \mathrm{~min}$ in these conditions, intracellular $\mathrm{Ca}^{2+}$ increased to $\sim 90 \mathrm{~nm}$. This value was significantly lower $(p<0.05)$ than that observed in 30K-stimulated control cultures. After $24 \mathrm{hr}$ of treatment, the intracellular calcium in $30 \mathrm{~K}-\mathrm{W} 13-$ and $30 \mathrm{~K}-$ W12-treated cells had increased to $98 \pm 7$ and $97 \pm 13.5 \mathrm{nM}$, respectively. These values are similar to those found in $30 \mathrm{~K}$ control cultures after the same period $(98 \pm 13 \mathrm{~nm})$ (Fig. $5 B)$. Taken together, these results confirm that W13 induces apoptotic 
cell death through a direct action on calmodulin and not through a blockade of the calcium influx (see Discussion).

\section{Inhibitors of PI-3 kinase did not block depolarization- promoted survival of MTNs}

Recent experiments reported by Miller et al. (1997) suggest a role of PI-3 kinase in neuronal survival induced by depolarization. We therefore investigated the possible involvement of PI-3 kinase in signaling pathways that promote cell survival in MTNs treated with high $\mathrm{K}^{+}$medium. To this end we used wortmannin, a PI-3 kinase inhibitor. It has been demonstrated that at a wortmannin concentration of $100 \mathrm{nM}$, the activity of PI-3 kinase was inhibited almost completely (Yano et al., 1993; Kimura et al., 1994; Okada et al., 1994a,b). The addition of wortmannin to MTNs maintained in $30 \mathrm{~K}$ did not have any effect on survival. The percentage of MTN survival in cultures treated with $100 \mathrm{~nm}$ wortmannin and $30 \mathrm{~K}$ was $79.4 \pm 4.2 \%$. This value is similar to that observed in cultures treated with $30 \mathrm{~K}$ alone $(84.1 \pm 4.7 \%)$. To confirm that PI-3K was not involved in the survival effect of depolarization, we studied the activation of this enzyme by the tyrosine phosphorylation of its p85 subunit. Thus, MTNs were depolarized for $1 \mathrm{~min}$ with $30 \mathrm{~K}^{+}$. Cytoplasmic lysates from these cells were subjected to immunoprecipitation with a specific anti-PTyr antibody (4G10) and submitted to Western blot analysis with an anti-p85 polyclonal antibody. This assay showed that depolarization failed to activate the PI-3K (Fig. 6A). The MTNs immunoprecipitates were compared with those of NGF-stimulated PC12 cells that were used as positive control of the experiment and that shown a clear band of tyrosine phosphorylated p85. The positive signal obtained with the anti-p85 antibody on western blots of MTNs cell lysates (Fig. 6B) discard the possibility that the lack of p85 signal in the MTNs immunoprecipitates of the Figure 6A was due to failure of the antibody to recognize the chicken $\mathrm{p} 85$ subunit of PI-3K. Taken together, these results suggest that activation of PI-3 kinase is not involved in the MTN survival promoted by membrane depolarization.

\section{Depolarization induces MAPK tyrosine phosphorylation in MTNs}

Our previous results show that the elevation of $\left[\mathrm{Ca}^{2+}\right]_{i}$ promotes MTN survival in the absence of neurotrophic support. Many neurotrophic factors promote neuronal survival through the activation of the MAPK pathway, the state of activation of which can be monitored by assessing the level of tyrosine phosphorylation of ERK1 and ERK2, two members of the MAPK family (Thomas et al., 1992; Rosen et al., 1994; Rusanescu et al., 1995). To determine whether the membrane depolarization is also able to activate the MAPK pathway, we compared the level of MAPK tyrosine phosphorylation in our experimental condition, i.e., $30 \mathrm{~K}$. As a negative control, nonstimulated (N.S.) MTNs were used. Cytoplasmic lysates of the cells were extracted and submitted to Western blot analysis for detection of tyrosine-phosphorylated proteins with the anti-PTyr antibody 4G10. The results (Fig. 6C) showed a protein, with an apparent molecular weight of $\sim 42 \mathrm{kDa}$ (designated as ERK2), that increased its state of tyrosine phosphorylation after $5 \mathrm{~min}$ of depolarization. This tyrosinephosphorylated protein was not detected in nonstimulated (N.S.) cells. ERK2 was immunoprecipitated from the same lysates with a specific anti-ERK2 antibody. When those immunoprecipitates were submitted to the same anti-phosphotyrosine analysis, a similar result was observed. Depolarization was able to specifically phosphorylate this protein on tyrosine residues (Fig. 6D).
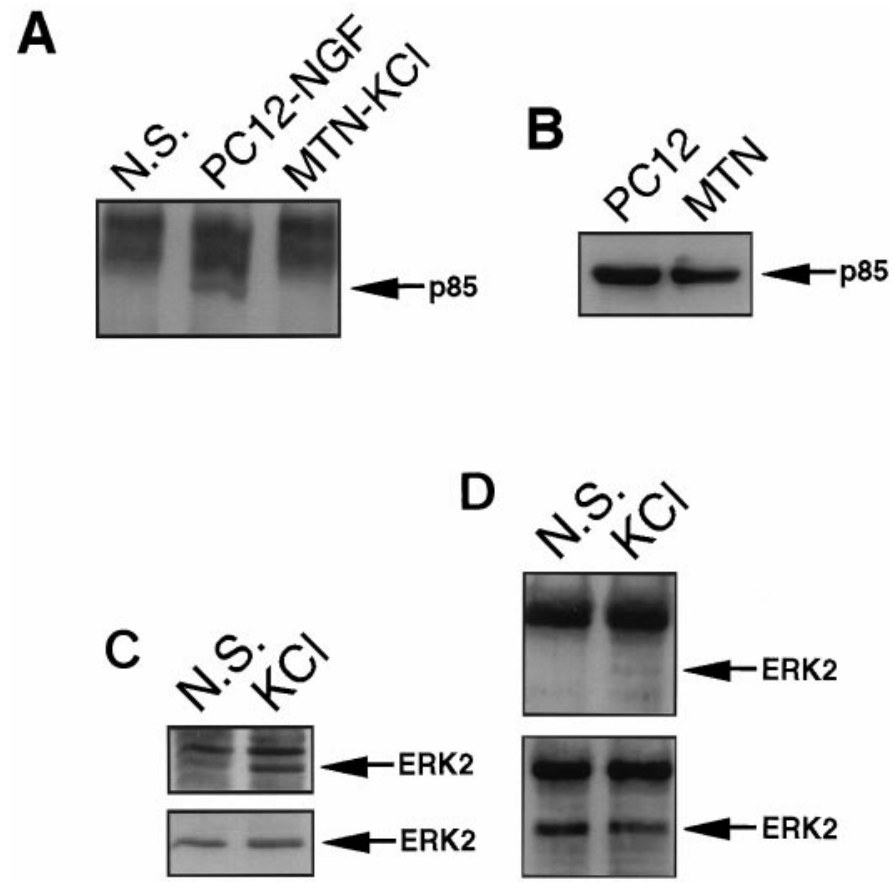

Figure 6. Effect of elevated extracellular $\mathrm{K}^{+}$levels on activation of MAPK and PI-3K. A, The p85 subunit of the PI-3K was immunoprecipitated from protein extracts of high potassium-treated MTNs $(\mathrm{MTN}-\mathrm{KCl})$ with the anti-PTyr antibody, and the immunoprecipitates were analyzed on Western blot with an anti-p85 antibody. p85 immunoprecipitates from NGF-treated PC12 cells (PC12-NGF) and from nonstimulated MTNs (N.S.) were used as positive and negative controls, respectively. $p 85$ labeled arrow indicates the position of the phosphorylated p85, which is evident only in the NGF-treated PC12 lane. B, PC12 and MTN cell lysates were analyzed on Western blot with an anti-p85 antibody to demonstrate that this antibody is able to recognize this protein in both lysates. p85-labeled arrow indicates the position of the $\mathrm{p} 85$ subunit. $C$, Tyrosine phosphorylation analysis of total cell extracts or $(D)$ ERK2 immunoprecipitates from nonstimulated (N.S.) or high potassium-stimulated MTNs cultures $(\mathrm{KCl})$. Western blots were probed with an anti-PTyr antibody (top panels) and reprobed after a stripping step with anti-pan-ERK monoclonal antibody (bottom panels). ERK2-labeled arrows indicate the position of ERK2 protein in blots.

Reblottings of the membranes that contained the cytoplasmic lysates or the immunoprecipitates with an anti-pan-ERK monoclonal antibody (Fig. 6C,D) confirmed the identity of the observed bands as the ERK2 kinase. Moreover, this result demonstrates that differences in band intensity between N.S. cells and treated cells were caused by the degree of phosphorylation and not differences in the protein content. We have also analyzed the state of phosphorylation of Trk in depolarized MTNs or PC12 cells by immunoprecipitating this protein with specific antibodies (pan-Trk antibodies) and submitting the immunoprecipitates to Western blot analysis using an anti-Ptyr antibody. We have never detected any autophosphorylative response to Trk in MTNs or PC12 cells stimulated with high $\mathrm{K}^{+}$in the culture medium, although there was a clear phosphorylation of the MAPK in their corresponding cell lysates (data not shown).

\section{Depolarization-induced MAPK activation was not blocked by calmodulin antagonists}

The cell survival experiments showed that the calmodulin antagonist W13 is able to block the effect of membrane depolarization on MTN survival at concentrations of $5 \mu \mathrm{g} / \mathrm{ml}$ or lower. To test whether this calmodulin antagonist has any effect on MAPK 


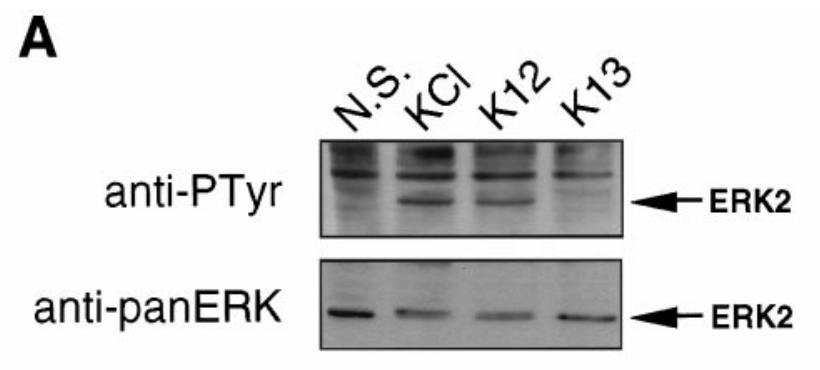

B

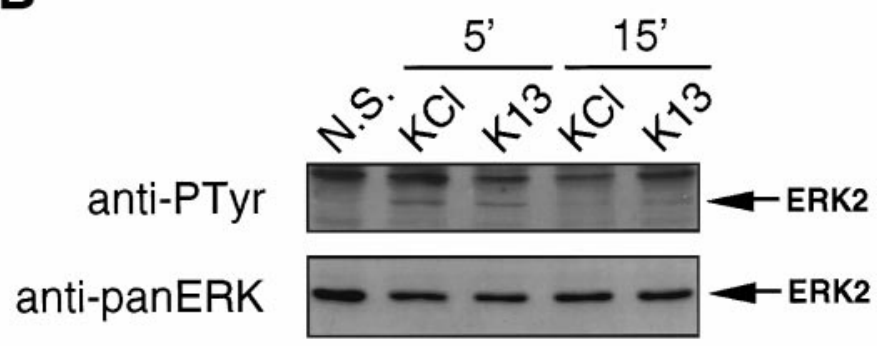

Figure 7. Effect of calmodulin antagonists on depolarization-induced MAPK activation. $A$, MTN cultures were pretreated for $3 \mathrm{hr}$ with 25 $\mu \mathrm{g} / \mathrm{ml}$ of W12 (K12) or $25 \mu \mathrm{g} / \mathrm{ml} \mathrm{W13} \mathrm{(K13)} \mathrm{or} \mathrm{left} \mathrm{untreated} \mathrm{(N.S.} \mathrm{and}$ $K C l)$. Then, cultures were stimulated for $5 \mathrm{~min}$ with high potassium (K12, $\mathrm{K13}$, and $\mathrm{KCl}$ ) or were left unstimulated (N.S.). Protein extracts were analyzed on Western blot with an anti-Ptyr antibody (top panel). Membranes were stripped and reprobed with an anti-pan-ERK monoclonal antibody (bottom panel). B, MTN cultures were pretreated for $3 \mathrm{hr}$ with $5 \mu \mathrm{g} / \mathrm{ml} \mathrm{W13} \mathrm{(K13)} \mathrm{or} \mathrm{left} \mathrm{untreated} \mathrm{(N.S.} \mathrm{and} \mathrm{KCl}$ ). Then, cultures were stimulated for $5\left(5^{\prime}\right)$ or $15\left(15^{\prime}\right)$ min with high potassium $(\mathrm{KCl}$ and $\mathrm{K13})$ or were left unstimulated (N.S.). Protein extracts were analyzed on Western blot with an anti-Ptyr antibody (top panel). Membranes were stripped and reprobed with the anti-pan-ERK antibody (bottom panel). ERK2-labeled arrows indicate the position of ERK2 protein in $A$ and $B$.

pathway activation in depolarized MTNs, tyrosine phosphorylation of ERK2 MAPK was monitored. In MTNs treated for 5 or 15 min with $30 \mathrm{mM} \mathrm{K}^{+}$, addition of $5 \mu \mathrm{g} / \mathrm{ml} \mathrm{W13} \mathrm{did} \mathrm{not} \mathrm{inhibit} \mathrm{the}$ tyrosine phosphorylation of ERK2 MAPK (Fig. 7B). The inhibition of ERK2 phosphorylation was observed only when the concentration of W13 was increased to $25 \mu \mathrm{g} / \mathrm{ml}$ (Fig. $7 A$ ). The inhibition was specific, because in the same experiment application of $25 \mu \mathrm{g} / \mathrm{ml}$ of the weaker calmodulin antagonist W12 did not have any effect on MAPK phosphorylation (Fig. 7A). These data suggest that calmodulin may play a primary role in the survival promoted by membrane depolarization without interrupting the signaling from membrane depolarization to the MAPK pathway.

\section{DISCUSSION}

In the present work, we have shown that elevated extracellular $\mathrm{K}^{+}$promoted MTN survival in the absence of neurotrophic support. Increased extracellular $\mathrm{K}^{+}$can prolong the survival of different types of nerve cells and can completely substitute the neurotrophic agents for in vitro survival of many populations of neurons (for review, see Franklin and Johnson, 1992). Our results show that $30 \mathrm{~mm} \mathrm{~K}^{+}$added to the culture medium promoted the survival of MTNs deprived of MEX. It is well known that elevated extracellular $\mathrm{K}^{+}$causes membrane depolarization on neurons. The consequence of membrane depolarization is the increase in $\left[\mathrm{Ca}^{2+}\right]_{i}$, which appears to be attributable to $\mathrm{Ca}^{2+}$ influx through dihydropyridine-sensitive L-type voltage-gated
$\mathrm{Ca}^{2+}$ channels. In accordance with these pharmacological studies, we have shown that depolarizing levels of $\mathrm{K}^{+}$promote the survival of embryonic chick MTNs by activating L-type $\mathrm{Ca}^{2+}$ channels. Our $\left[\mathrm{Ca}^{2+}\right]_{\mathrm{i}}$ measurements with fura-2 AM showed that membrane depolarization caused a sustained increment in the intracellular $\mathrm{Ca}^{2+}$ level, which was prevented by the application of the L-type $\mathrm{Ca}^{2+}$ channel antagonists. Therefore, it can be concluded that the depolarization-induced $\mathrm{Ca}^{2+}$ increase was caused by $\mathrm{Ca}^{2+}$ influx from the extracellular compartment.

MTN response to membrane depolarization differs depending on the stage of maturation of the cells in culture. Thus, when MTNs were treated with high $\mathrm{K}^{+} 12$ or $24 \mathrm{hr}$ after plating, this treatment did not promote as much MTN survival as MEX. However, when high $\mathrm{K}^{+}$was applied after 2 or $3 \mathrm{~d}$ in culture with MEX, 30K supported a percentage of MTN survival similar to that of MEX. It is possible that although MTNs in ovo already show an elevated density of $\mathrm{L}-\mathrm{Ca}^{2+}$ current at the corresponding developmental age (Mccobb et al., 1989), MTNs in vitro need a longer time to express a sufficient quantity of L-type $\mathrm{Ca}^{2+}$ channels to allow significant $\mathrm{Ca}^{2+}$ currents in response to depolarization. Similar results have been reported by Franklin et al. (1995), who showed that superior cervical ganglion neurons did not survive in response to increases in $\left[\mathrm{Ca}^{2+}\right]_{\mathrm{i}}$ until the cells had been cultured for $3 \mathrm{~d}$ in the presence of NGF. However, intracellular $\mathrm{Ca}^{2+}$ measurements on addition of $30 \mathrm{mM} \mathrm{K}^{+}$to the MTN culture medium did not differ between neurons cultured for 1,2 , or $3 \mathrm{~d}$ in the presence of MEX (data not shown). These results raise the possibility that factors other than the increase in $\left[\mathrm{Ca}^{2+}\right]_{\mathrm{i}}$ are needed for neurons to develop a survival response to membrane depolarization that is able to prevent neuronal death after trophic deprivation. One possible explanation of this result would be that MTNs need to recover from the damage caused by dissociation procedure. It is also possible that the developmental age of the motoneurons is important because it could be related to the acquisition of some additional elements that allow the survival as a consequence of the intracellular calcium increases. This would be difficult to approach experimentally because purification of chicken motoneurons older than 6 embryonic days is very difficult technically and has never been reported.

One important issue examined in the present report is how chronic membrane depolarization is able to prevent MTN death after neurotrophic deprivation. A possible explanation would be that high $\mathrm{K}^{+}$medium might induce the release from other cells of neurotrophic factors for this population of neurons; however, several results argue against this possibility. Our cultures are $>95 \%$ pure in MTNs and do not contain glial cells (Comella et al., 1994). The small percentage of non-MTN cells corresponds to other types of neuronal cells. Therefore, the possibility that glial-derived neurotrophic factors such as GDNF, which have been reported to be neurotrophic for MTN (Henderson et al., 1994; Oppenheim et al., 1995; Yan et al., 1995), are released seems unlikely. Additionally, MTN survival attributable to high $\mathrm{K}^{+}$did not significantly improve in high- versus low-density cultures (data not shown). Similar results have been reported by other groups that have described a relative insensitivity to changes in cell density of the survival response to high $\mathrm{K}^{+}$ (Collins and Lile, 1989; Franklin et al., 1995). However, a trophic factor might be produced in small quantities by depolarized motoneurons having local effects on the neighboring cells. According to this hypothesis, Ghosh et al. (1994) demonstrated recently that high $\mathrm{K}^{+}$induces $\mathrm{BDNF}$ expression in cultured embryonic cortical neurons from rats. In our culture system, 
BDNF has an obvious survival-promoting effect on 3-d-old MTN cultures but not on 1- and 2-d-old MTN cultures (J. X. Comella, unpublished results). It should be noted here that after $48 \mathrm{hr}$ in culture MTNs showed a full rescuing response to depolarization. Moreover, we have never seen any autophosphorylative response of Trk in response to membrane depolarized in MTNs. Accordingly, in PC12 cells, the addition of high potassium to the culture medium is able to activate MAPK without inducing Trk autophosphorylation. Therefore, our results suggest strongly that depolarization promotes neuronal survival directly by affecting some process occurring within the cell rather than indirectly by autocrine BDNF release. However, we cannot rule out completely that part of the rescuing effect of $30 \mathrm{~K}$ may depend on the synthesis and release of BDNF or other neurotrophic factors in cultures older than $48 \mathrm{hr}$.

Several reports using pharmacological antagonists of calmodulin (calmidazolium, W7, or trifluoperazine) have suggested that this molecule mediates the survival effects of high $\mathrm{K}^{+}$(Gallo et al., 1987; Hack et al., 1993; Franklin et al., 1995). However, the major drawback of these inhibitors is that they also reduce the $\mathrm{Ca}^{2+}$ current induced by high $\mathrm{K}^{+}$, because they functionally block the voltage-dependent $\mathrm{Ca}^{2+}$ channels (Greenberg et al., 1987; Doroshenko et al., 1988; Franklin et al., 1995). Therefore, it cannot be determined whether the effects of these drugs were attributable to the blockade of calcium entry or an effect on an intracellular pathway related to neuronal survival. In the present work we have used the calmodulin inhibitors W12 and W13, which are related structurally. The only difference between both molecules is a chlorine residue present in W13 that renders this compound much more effective as a calmodulin inhibitor than W12. Therefore, W12 may be used as a control for the side effects of W13 on $\mathrm{Ca}^{2+}$ channels (Hidaka et al., 1981; Hidaka and Tanaka, 1983). W13 was able to block the survival response caused by membrane depolarization in our culture system, whereas W12 was ineffective. Data obtained by scoring apoptotic MTNs with a nuclear DNA staining support the view that W13 blocks the survival response, thus inducing apoptotic cell death. On the other hand, when $\mathrm{Ca}^{2+}$ measurements were performed in MTNs treated with the calmodulin inhibitors, both of them significantly and similarly reduced the initial elevation of $\left[\mathrm{Ca}^{2+}\right]_{i}$ after $30 \mathrm{~K}$ addition, whereas no differences were observed between the long-term effects of W13 and W12 on $\left[\mathrm{Ca}^{2+}\right]_{\mathrm{i}}$. Taken together, these results suggest that W13 inhibits the biological effect of membrane depolarization by directly blocking the calmodulin function rather than preventing calcium entry. At the same time, the differential effects of W12 and W13 on survival exclude a functional relevance of the initial $\left[\mathrm{Ca}^{2+}\right]_{i}$ peak, which was suppressed similarly by both drugs.

Recent experiments by several groups have shown that increases in $\left[\mathrm{Ca}^{2+}\right]_{i}$ activate the MAPK pathway (for review, see Finkbeiner and Greenberg, 1996; Segal and Greenberg, 1996). Our results showed that MAPK pathway is activated after membrane depolarization in MTNs. This activation is not involved in depolarization-induced neuronal survival, because calmodulin antagonists did not block the MAPK tyrosine phosphorylation at doses that are able to inhibit the neuronal survival.

It is known that in NGF-treated PC12 cells, the PI-3 kinase signaling pathway mediates neuronal survival (Yao and Cooper, 1995). In our culture system the presence of the PI-3 kinase inhibitor wortmannin did not suppress the neuronal survival promoted by elevated extracellular $\mathrm{K}^{+}$. Moreover, no phosphorylation of the p85 subunit of PI-3K was detected in response to depolarization. These results suggest that the PI-3 kinase pathway is not relevantly involved in the survival of chicken depolarized MTNs. At present we do not know whether PI-3K is relevant for MTN survival induced by other mechanisms, such as specific neurotrophic factors. Recent reports from other laboratories showed contradictory results about the role of the activation of this pathway in promoting cell survival of depolarized primary cultured neurons (D’Mello et al., 1997; Miller et al., 1997). Because a given neurotrophin can activate different signaling pathways that mediate neuronal survival in different neuronal populations (Borasio et al., 1993), we cannot rule out the possibility that MTN survival is mediated by unknown PI-3 kinase- and MAPK-independent pathways.

In conclusion, our results show that increases in $\left[\mathrm{Ca}^{2+}\right]_{\mathrm{i}}$ after membrane depolarization are able to promote neuronal survival by PI-3K- and MAPK-independent pathways in chicken MTNs. The main intracellular mediator of this effect appears to be calmodulin, and therefore proteins regulated by calmodulin should be major targets of analysis when the study of the survivalpromoting effects of intracellular calcium is approached.

\section{REFERENCES}

Barde YA (1989) Trophic factors and neuronal survival. Neuron 2:1525-1534.

Borasio GD, Markus A, Wittinghofer A, Barde YA, Heumann R (1993) Involvement of Ras p21 in neurotrophin-induced response of sensory, but not sympathetic neurons. J Cell Biol 121:665-672.

Collins F, Lile JD (1989) The role of dihydropyridine-sensitive voltagegated calcium channels in potassium-mediated neuronal survival. Brain Res 502:99-108.

Collins F, Schmidt MF, Guthrie PB, Kater SB (1991) Sustained increase in intracellular calcium promotes neuronal survival. J Neurosci 11:2582-2587.

Comella JX, Sanz-Rodriguez C, Aldea M, Esquerda JE (1994) Skeletal muscle-derived trophic factors prevent motoneurons from entering an active cell death program in vitro. J Neurosci 14:2674-2686.

D’Mello SR, Borodezt K, Soltoff SP (1997) Insulin-like growth factor and potassium depolarization maintain neuronal survival by distinct pathways: possible involvement of PI 3-kinase in IGF-1 signaling. J Neurosci 17:1548-1560.

Doroshenko PA, Kostyuk PG, Lukyanetz EA (1988) Modulation of calcium current by calmodulin antagonists. Neuroscience 27:1073-1080.

Dudek H, Datta SR, Franke TF, Bimbaum MJ, Yao R, Cooper GM, Segal RA, Kaplan DR, Greenberg ME (1997) Regulation of neuronal survival by the serine-threonine protein kinase Akt. Science 275:661-665.

Finkbeiner S, Greenberg ME (1996) $\mathrm{Ca}^{2+}$-dependent routes to Ras: mechanisms for neuronal survival, differentiation, and plasticity? Neuron 16:233-236.

Franklin JL, Johnson EM (1992) Suppression of programmed neuronal death by sustained elevation of cytoplasmic calcium. Trends Neurosci 15:500-508.

Franklin JL, Sanz-Rodriguez C, Juhasz A, Deckwerth TL, Johnson EM (1995) Chronic depolarization prevents programmed death of sympathetic neurons in vitro but does not support growth: requirement for $\mathrm{Ca}^{2+}$ influx but not Trk activation. J Neurosci 15:643-664.

Gallo V, Kingsbury A, Balazs R, Jorgensen OS (1987) The role of depolarization in the survival and differentiation of cerebellar granule cells in culture. J Neurosci 7:2203-2213.

Ghosh A, Carnahan J, Greenberg ME (1994) Requirement for BDNF in activity-dependent survival of cortical neurons. Science 263: $1618-1623$.

Greenberg DA, Carpenter CL, Messing RO (1987) Interaction of calmodulin inhibitors and protein kinase $\mathrm{C}$ inhibitors with voltagedependent calcium channels. Brain Res 404:401-404.

Grynkiewicz D, Poenie M, Tsien RY (1985) A new generation of calcium indicators with greatly improved fluorescence properties. J Biol Chem 260:3440-3450.

Hack N, Hidaka H, Wakerfield MJ, Balazs R (1993) Promotion of granule cell survival by high $\mathrm{K}^{+}$or excitatory amino acid treatment and 
$\mathrm{Ca}^{2+} /$ calmodulin-dependent protein kinase activity. Neuroscience 57:9-20.

Henderson CE, Phillips HS, Pollock RA, Davies AM, Lemeulle C, Armanini M, Simpson LC, Moffet B, Vandlen RA, Koliatsos VE, Rosenthal A (1994) GDNF: a potent survival factor for motoneurons present in peripheral nerve and muscle. Science 266:1062-1064.

Hidaka H, Tanaka T (1983) Naphthalenesulfonamides as calmodulin antagonists. In: Methods in enzymology (Means AR, O'Malley BW, eds), pp 185-193. New York: Academic.

Hidaka H, Sasaki Y, Tanaka T, Endo T, Ohno S, Fujii H, Nagata T (1981) $N$-(6-aminohexyl)-5-chloro-1-naphthalenesulfonamide, a calmodulin antagonist inhibits cell proliferation. Proc Natl Acad Sci USA 78:4354-4357.

Johnson EM, Koike T, Franklin J (1992) A calcium set-point hypothesis of neuronal dependence on neurotrophic factor. Exp Neurol 115:163-166.

Kimura K, Hattori S, Kabuyama Y, Shizawa Y, Takayanagi J, Nakamura S, Toki S, Matsuda Y, Onodera K, Fukui Y (1994) Neurite outgrowth of PC12 cells is suppressed by wortmannin, a specific inhibitor of phosphatidylinositol 3-kinase. J Biol Chem 269:18961-18967.

Koike T, Tanaka S (1991) Evidence that nerve growth factor dependence of sympathetic neurons for survival in vitro may be determined by levels of cytoplasmic free $\mathrm{Ca}^{2+}$. Proc Natl Acad Sci USA 88:3892-3896.

Koike T, Martin DP, Johnson Jr EM (1989) Role of $\mathrm{Ca}^{2+}$ channels in the ability of membrane depolarization to prevent neuronal death induced by trophic-factor deprivation: evidence that levels of internal $\mathrm{Ca}^{2+}$ determine nerve growth factor dependence of sympathetic ganglion cells. Proc Natl Acad Sci USA 86:6421-6425.

Larmet Y, Dolphin AC, Davies AM (1992) Intracellular calcium regulates the survival of early sensory neurons before they become dependent on neurotrophic factors. Neuron 9:563-574.

Lipscombe D, Madison DV, Poenie M, Reuter H, Tsien RW, Tsien RY (1988) Imaging of cytosotic $\mathrm{Ca}^{2+}$ stores and $\mathrm{Ca}^{2+}$ channels in sympathetic neurons. Neuron 1:355-365.

Mccobb DP, Best PM, Beam KG (1989) Development alters the expression of calcium currents in chick limb motoneurons. Neuron 2:1633-1643.

Miller TM, Tansey MG, Johnson EM, Creedon DJ (1997) Inhibition of phosphatidylinositol 3-kinase activity blocks depolarization- and insulin-like growth factor I-mediated survival of cerebellar granule cells. J Biol Chem 272:9847-9853.

Mobley WC, Schenker A, Shooter EM (1976) Characterization and isolation of proteolytically modified nerve growth factor. Biochemistry 15:5543-5552.

Murrell RD, Tolkosky AM (1993) Role of voltage-gated $\mathrm{Ca}^{2+}$ channels and intracellular $\mathrm{Ca}^{2+}$ in rat sympathetic neuron survival and function promoted by high $\mathrm{K}^{+}$and cyclic AMP in the presence or absence of NGF. Eur J Neurosci 5:1261-1272.

Nowycky MC, Fox AP, Tsien RV (1985) Long-opening mode of gating of neuronal calcium channels and its promotion by the dihydropyridine calcium agonist Bay K 8644. Proc Natl Acad Sci USA 82:2178-2182.

Okada T, Kawano Y, Sakakibara T, Hazeki O, Ui M (1994a) Essential role of phosphatidylinositol 3-kinase in insulin-induced glucose transport and antilipolysis in Ras adipocytes. J Biol Chem 269:3568-3573.

Okada T, Sakuma L, Fukui Y, Hazeki O, Ui M (1994b) Blockade of chemotactic peptide-induced stimulation of neutrophils by wortmannin as a result of selective inhibition of phosphatidylinositol 3-kinase. J Biol Chem 269:3563-3567.

Oppenheim RW (1989) The neurotrophic theory and naturally occurring motoneuron death. Trends Neurosci 12:252-255.

Oppenheim RW (1991) Cell death during development of the nervous system. Annu Rev Neurosci 14:453-501.

Oppenheim RW, Houenou LJ, Johnson JE, Lin LFH, Li LX, Lo AC, Newsome AL, Prevette DM, Wang SW (1995) Developing motor neurons rescued from programmed and axotomy-induced cell death by GDNF. Nature 373:344-346.

Rosen LB, Ginty DD, Weber MJ, Greenberg ME (1994) Membrane depolarization and calcium influx stimulate MEK and MAP kinase via activation of Ras. Neuron 12:1207-1221.

Rusanescu G, Qi H, Thomas SM, Brugge JS, Halegoua S (1995) Calcium influx induces neurite growth through a Src-Ras signalling cassette. Neuron 15:1415-1425.

Schlessinger J (1993) How receptor tyrosine kinases activate Ras. Trends Biochem Sci 18:273-275.

Segal RA, Greenberg ME (1996) Intracellular signalling pathways activated by neurotrophic factors. Annu Rev Neurosci 19:463-489.

Snider WD, Johnson EM (1989) Neurotrophic molecules. Ann Neurol 26:489-506.

Striessing J, Goll A, Mossburger K, Glossmann H (1986) Purified calcium channels have three allosterically coupled drug receptors. FEBS Lett 197:204-210.

Thomas SM, Demarco M, Darcangelo G, Halegoua S, Brugge JS (1992) Ras is essential for nerve growth factor-induced and phorbol esterinduced tyrosine phosphorylation of Map kinases. Cell 68:1031-1040.

Vemuri GS, McMorris FA (1996) Oligodendrocytes and their precursors require phosphatidylinositol 3-kinase signaling for survival. Development 122:2529-2537.

Yan Q, Matheson C, Lopez OT (1995) In vivo neurotrophic effects of GDNF on neonatal and adult facial motor neurons. Nature 373:341-344.

Yano H, Nakanishi S, Kimura K, Hanai N, Saitoh Y, Fukui Y, Nonomura Y, Matsuda Y (1993) Inhibition of histamine secretion by wortmannin through the blockade of phosphatidylinositol 3-kinase in RBL-2H3 cells. J Biol Chem 268:25846-25856.

Yao RJ, Cooper GM (1995) Requirement for phosphatidylinositol-3 kinase in the prevention of apoptosis by nerve growth factor. Science 267:2003-2006. 